\title{
Overexpression of periostin predicts poor prognosis in non-small cell lung cancer
}

\author{
LING-ZHI HONG ${ }^{1,2}$, XIAO-WEI WEI ${ }^{1}$, JIN-FEI CHEN $^{1}$ and YI SHI $^{2}$ \\ ${ }^{1}$ Department of Oncology, Nanjing First Hospital, Nanjing Medical University, Nanjing, Jiangsu 210006; \\ ${ }^{2}$ Department of Respiratory and Critical Care Medicine, Jinling Hospital, \\ Nanjing University School of Medicine, Nanjing, Jiangsu 210002, P.R. China
}

Received December 12, 2012; Accepted July 19, 2013

DOI: $10.3892 / \mathrm{ol} .2013 .1590$

\begin{abstract}
The periostin protein, encoded by the POSTN gene, is a component of the extracellular matrix, which is expressed by fibroblasts and has been observed in a variety of human malignancies. The present study aimed to detect the expression of periostin in the tissues of non-small cell lung cancer (NSCLC) patients and benign lung tumors, and to correlate the results with the clinicopathological data of the subjects, in order to evaluate periostin as a potential prognostic marker. In total, 49 NSCLC patients and 6 benign lung tumors were included in this study. The protein level of periostin was detected in paired normal/paratumor/cancer tissues by a western blot analysis and the mRNA level in paired normal/cancer tissues was detected by quantitative polymerase chain reaction (qPCR). The results were then correlated with established biological and prognostic factors. Immunohistochemistry was used to confirm the location of periostin in the NSCLC tissues. Uni- and multivariate analyses were performed using Cox's proportional hazards regression model. The protein level of periostin was elevated in the cancer tissue of the NSCLC patients compared with the normal $(\mathrm{P}=0.017)$ and paratumor $(\mathrm{P}=0.000)$ tissues. The expression level in the male patients was much higher than in the female patients at the protein $(\mathrm{P}=0.001)$ and mRNA $(\mathrm{P}=0.010)$ levels. The mRNA level in the non-adenocarcinoma (non-ADC) patients was much higher than in the adenocarcinoma (ADC) patients $(\mathrm{P}=0.029)$. Periostin was demonstrated higher expression at the protein level in the pseudotumors and tuberculosis patients than in the adjacent $(\mathrm{P}=0.016)$ and surrounding tissues $(\mathrm{P}=0.001)$. Immunostaining indicated that high levels of periostin were present in the mesenchymal areas, but not in the cancer cells themselves. The patients with
\end{abstract}

Correspondence to: Dr Yi Shi, Department of Respiratory and Critical Care Medicine, Jinling Hospital, Nanjing University School of Medicine, 305 East Zhongshan Road, Nanjing, Jiangsu 210002, P.R. China

E-mail: shiyi56@126.com

Key words: periostin, non-small cell lung cancer, overexpressed, prognostic factor tumors exhibiting high-level periostin expression showed a significantly shorter survival time $(\mathrm{P}=0.036, \log$-rank test). The 3-year survival rate was $81.5 \%$ for patients with low-level periostin expression (periostin-L; $n=27$ ) and $45.4 \%$ for patients with high-level periostin expression (periostin-H; $n=22$ ). Similarly, pathological node (pN) status was a significant prognostic marker in the univariate Cox survival analysis. Notably, periostin-H expression was also identified as an independent prognostic factor by the multivariate analysis $(\mathrm{P}=0.011)$. These results showed that the overexpression of periostin predicts a poor prognosis, therefore it may be regarded as a novel molecule in the progression and development of NSCLC. The results provide an additional target for the adjuvant treatment of NSCLC.

\section{Introduction}

Lung cancer is the most commonly diagnosed type of cancer (1.6 million cases each year) and the most common cause of cancer mortality (1.18 million mortalities each year). The number of new cases and mortalities is progressively increasing every year. Lung cancer is not easily diagnosed. Only $\sim 10 \%$ of lung cancer patients are alive 5 years after diagnosis. Lung cancer is the leading cancer site in males, comprising $17 \%$ of total new cancer cases and $23 \%$ of total cancer mortalities (1). Non-small cell lung cancer (NSCLC) is the most common type of lung cancer. The development and progression of NSCLC is a complex process, and the tumor microenvironment plays an important role. The tumor microenvironment is composed of structural (extracellular matrix), soluble (cytokines, proteases and hormones) and cellular components (tumor cells, fibroblasts, inflammatory cells, vascular and lymphatic endothelial cells, vascular smooth muscle cells and pericytic cells). In 1993, Takeshita et al (2) identified an 811-amino acid protein, named osteoblast specific factor-2 (OSF-2), which was secreted by the mouse MC3T3-E1 osteoblastic cell line. OSF-2 has a typical signal sequence, followed by a cysteine-rich domain (EMI domain), a 4-fold repeated domain and a C-terminal domain. The 4-fold repeated domain shows homology with the insect protein, fasciclin I (2). Each of the 4-fold repeated domains has 150 amino acids, and 90-100 of these 150 amino acids are highly conserved, forming an area called the fas domain. As 
OSF-2 is also expressed by the periosteum and periodontal ligament, this protein was renamed periostin (3). In humans, the periostin gene (POSTN) is located on chromosome 13, at map position 13q13.3, and the protein is 835 amino acids in size and $90 \mathrm{kDa}$ in molecular weight (4). Mouse and human periostin share $89.2 \%$ amino acid identity overall and $90.1 \%$ identity in their mature forms.

Periostin is expressed at the mRNA level by the majority of normal adult tissues, including the aorta, stomach, lower gastrointestinal tract, placenta, uterus and breast. The expression of periostin is high in fetal tissue at the mRNA and protein levels (5). Periostin protein expression is observed in normal adult tissues, including the adrenal glands, lung, thyroid, stomach, colon, vagina, ovary, testis and prostate, by western blot analysis (6). Periostin may be induced by transforming growth factor- $\beta$ (TGF- $\beta$ ) (7) and Bmp-2 (8), and is involved in osteoblast recruitment, attachment and spreading (3). Periostin is considered to be a regulator of cardiac remodeling and hypertrophy and may be a suitable pharmacological target to mitigate heart failure (9).

Recently, periostin was identified as a novel factor in the growth, invasion, angiogenesis and metastasis of numerous types of tumors. Periostin is overexpressed in various types of human cancer tissues, including ovarian cancer (5), cholangiocarcinoma (10), breast cancer (11), colon cancer (12), esophageal cancer (13), head and neck cancer (14), and pancreatic ductal adenocarcinoma (ADC) (15). Notably, periostin expression is well correlated with malignant behavior, including growth, invasion, angiogenesis, metastasis and poor survival in ovarian cancer (5), cholangiocarcinoma (10), breast cancer (11), colon cancer (12), esophageal cancer (14) and pancreatic ductal ADC (15).

Periostin has also been detected in the serum of NSCLC by chemiluminescence assays. Notably, a previous study identified no significant difference between NSCLC patients and normal controls, and there was also no correlation between the serum periostin level and gender, stage, bone metastasis, lymph node status or primary tumor status. However, the NSCLC patients with high periostin levels had significantly poorer survival than the patients with normal periostin levels (16). Periostin mRNA has been shown to be upregulated in NSCLC tissue in relation to normal lung tissue, and also to be correlated with adeno cell subtype and higher tumor grade (17).

However, little information is available on the expression of periostin protein in NSCLC cancer tissues, and the correlation between periostin expression and the clinicopathological characteristics of NSCLC patients is unknown. Previously, we identified that serum periostin was elevated in NSCLC patients compared with normal healthy volunteers, and showed that periostin promotes the proliferation and migration of A549 cells by inducing vimentin and $\mathrm{N}$-cadherin expression and downregulating E-cadherin expression (18). In the present study, the mRNA and protein level of periostin in NSCLC and its correlation with established biological and prognostic factors were investigated. To provide evidence that the inactivation of the periostin gene is a common event in NSCLC, periostin gene expression was examined at the transcriptional and translational levels in 49 paired normal/paratumor/cancer tissues, and the correlation between periostin expression and prognosis in NSCLC was assessed.
Table I. Characteristics of the patients with primary non-small cell lung cancer (western blot analysis and qPCR).

\begin{tabular}{|c|c|}
\hline Characteristics & Value \\
\hline Total patients, n (\%) & $49(100)$ \\
\hline Age, years ${ }^{a}$ & $57.132 \pm 1.743$ \\
\hline \multicolumn{2}{|l|}{ Gender, n (\%) } \\
\hline Male & $38(77)$ \\
\hline Female & $11(23)$ \\
\hline \multicolumn{2}{|l|}{ Age, n (\%) } \\
\hline$<60$ years & $27(55)$ \\
\hline$\geq 60$ years & $22(45)$ \\
\hline \multicolumn{2}{|c|}{ Histological type, n (\%) } \\
\hline $\mathrm{ADC}$ & $35(71)$ \\
\hline Non-ADC & $14(29)$ \\
\hline \multicolumn{2}{|l|}{ Stage, n (\%) } \\
\hline $\mathrm{I}$ & 15 \\
\hline II & 10 \\
\hline $\mathrm{I}+\mathrm{II}$ & $25(51)$ \\
\hline III & 23 \\
\hline IV & 1 \\
\hline III+IV & $24(49)$ \\
\hline \multicolumn{2}{|c|}{ Tumor size and invasiveness, $\mathrm{n}(\%)$} \\
\hline $\mathrm{T} 1$ & 11 \\
\hline $\mathrm{T} 2$ & 28 \\
\hline $\mathrm{T} 1+\mathrm{T} 2$ & $39(79)$ \\
\hline $\mathrm{T} 3$ & 5 \\
\hline $\mathrm{T} 4$ & 5 \\
\hline $\mathrm{T} 3+\mathrm{T} 4$ & $10(21)$ \\
\hline \multicolumn{2}{|c|}{ Lymph node status, n (\%) } \\
\hline+ & $25(51)$ \\
\hline- & $24(49)$ \\
\hline \multicolumn{2}{|c|}{ Smoking history, n (\%) } \\
\hline$\geq 20$ pack year & $25(51)$ \\
\hline$<20$ pack year & $24(49)$ \\
\hline
\end{tabular}

${ }^{\text {aData }}$ are presented as the mean \pm SEM. qPCR, quantitative polymerase chain reaction; ADC, adenocarcinoma.

\section{Materials and methods}

Patients. Lung specimens from cancer tissues and paired paratumor tissues (with 1-2 cm distance from tumor edge) and normal tissues (with $>5 \mathrm{~cm}$ distance from tumor edge) from 49 NSCLC patients (Table I) and 6 benign lung tumors (including 3 inflammatory pseudotumors and 3 pulmonary tuberculosis cases), who underwent pulmonary resection surgery, were included in this study. The samples were obtained by the Department of Cardiothoracic Surgery of Jinling Hospital (Nanjing, Jiangsu, China) between June 2007 and June 2008. All diagnoses were based on pathological evidence. Patients were grouped according to the size of the primary tumor $(\mathrm{T})$, nodal involvement $(\mathrm{N})$ and distant metastasis (M) to TNM stages I-IV according to the World Health Organization criteria for the TNM system and 
staged appropriately. Patients did not receive chemo-, radio- or immunotherapy prior to surgery. The tissues were snap frozen and stored at $-80^{\circ} \mathrm{C}$ until use. This study was authorized by the principle committee of Jinling Hospital. Written informed consent was obtained from the patients.

Protein extraction and western blot analysis. Frozen tissues were washed twice with ice-cold phosphate-buffered saline (PBS), and homogenized on ice in 10 volumes (w/v) of lysis buffer [0.1\% SDS, $50 \mathrm{mM}$ Tris- $\mathrm{HCl}$ (pH 7.5) 1\% NP-40, $150 \mathrm{mM} \mathrm{NaCl}, 1 \mathrm{mM}$ Triton X-100, $1 \mathrm{mM}$ EDTA] containing complete protease inhibitor (PMSF+P8340). Subsequent to incubation on ice for $1 \mathrm{~h}$ and centrifugation at $12,000 \mathrm{xg}$ for $15 \mathrm{~min}$ at $4^{\circ} \mathrm{C}$, the supernatant was collected and stored at $-70^{\circ} \mathrm{C}$. The protein concentration was measured by the bicinchoninic acid (BCA) protein assay (Sigma, St. Louis, MO, USA). A total of $100 \mu \mathrm{g}$ protein was separated by $5-10 \%$ SDS-PAGE. Proteins were then transferred to polyvinylidene difluoride (PVDF) membranes (Bio-Rad, Hercules, CA, USA), which were saturated by incubation for $2 \mathrm{~h}$ with $5 \%$ skimmed dry milk in Tris-buffered saline (TBS) $/ 0.05 \%$ Tween-20 at $37^{\circ} \mathrm{C}$. The membranes were then incubated with the rabbit polyclonal anti-periostin antibody (ab14041, 1:1,000; Abcam, Cambridge, MA, USA) overnight at $4^{\circ} \mathrm{C}$ in blocking buffer $(5 \%$ skimmed dry milk in TBS/0.05\% Tween-20). Subsequent to being washed 4 times ( 5 min each) with TBS $/ 0.05 \%$ Tween-20, the membranes were incubated with anti-rabbit immunoglobulin labeled with horseradish peroxidase (ab6721, 1:2,000; Abcam) at $37^{\circ} \mathrm{C}$ in blocking buffer. After $1 \mathrm{~h}$ of incubation, the membranes were washed 4 times ( 5 min each) with TBS/ $0.1 \%$ Tween-20. Chemiluminescence was detected with an ECL western blot analysis detection kit (Pierce Biotechnology, Inc., Rockford, IL, USA), according to the manufacturer's instructions, and the results were quantified by densitometry using an Image System (GelDoc 2000; Bio-Rad). Polyclonal anti- $\beta$-actin (a housekeeping protein used as a loading control to assure equal amounts of protein in all lanes) antibody was used as a control.

RNA extraction and cDNA synthesis. Total RNA was isolated from the frozen tissue with TRIzol (Invitrogen, Carlsbad, CA, USA). Using random hexamer primers, $2 \mu \mathrm{g}$ RNA was reverse transcribed to cDNA with a PrimeScript ${ }^{\mathrm{TM}}$ 1st Strand cDNA Synthesis kit (Takara Biotechnology, Inc., Shiga, Japan).

Quantitative polymerase chain reaction ( $q P C R)$. Primers for POSTN and glyceraldehyde-3-phosphate dehydrogenase (GAPDH) were designed and synthesized by Takara Biotechnology, Co., Ltd. (Dalian, China). The basic information of the primers including gene name, National Center for Biotechnology Information (NCBI) reference, forward primer, reverse primer and product size (bp), respectively, were as follows: POSTN, NM_006475, CATTGATGGAGTGCCTGT GGA, CAATGAATTTGGTGACCTTGGTG and 167; and GAPDH, NM_002046, GCACCGTCAAGGCTGAGAAC, TGGTGAAGACGCCAGTGGA and 138.qPCR was performed in triplicate for each sample in a $25-\mu 1$ reaction mixture, which consisted of template DNA $(2 \mu \mathrm{l})$, primers $(0.2 \mu \mathrm{M})$, ROX

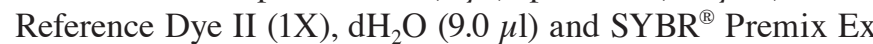
Taq [1X; SYBR Premix Ex Taq (perfect real-time) kit; Takara].

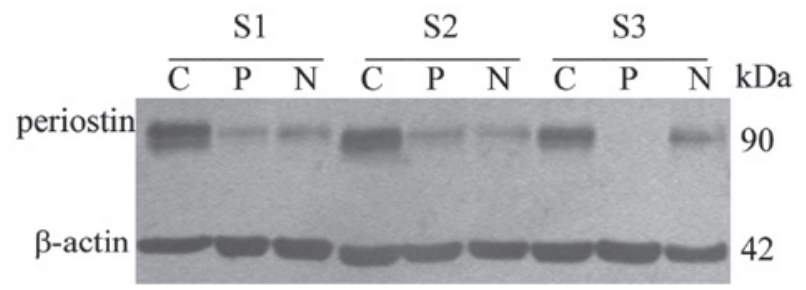

Figure 1. Representative results of periostin protein expression in different lung tissues. Lane C, cancer tissue; lane P, paratumor tissue; lane N, normal tissue. Samples: S1, S2 and S3. kDa, molecular weight.

PCR was performed using a Stratagene Mx3005P instrument (Stratagene, La Jolla, CA, USA) with the following thermal settings: 1 cycle of $10 \mathrm{sec}$ at $95^{\circ} \mathrm{C}$ and 45 cycles of $5 \mathrm{sec}$ at $95^{\circ} \mathrm{C}$ and $20 \mathrm{sec}$ at $60^{\circ} \mathrm{C}$. According to the method tested by Tichopad, the relative expression ratio (RR) of the POSTN was calculated based on amplication efficiencies and the cycle threshold comparative with a reference gene (GAPDH) in a sample.

Immunohistochemistry. Six paraffin sections of tumor were selected for analysis. Immunohistochemical staining was performed on 4- $\mu \mathrm{m}$ formalin-fixed, paraffin-embedded tissue sections. The slides were deparaffinized in xylene and dehydrated in a graded ethanol series. Endogenous peroxidase was blocked with $3 \% \mathrm{H}_{2} \mathrm{O}_{2}$ in methanol for $15 \mathrm{~min}$. The primary antibody that was used was the rabbit polyclonal anti-periostin antibody (ab14041, 1:200; Abcam). Immunohistochemical staining was performed using the Envision ${ }^{\mathrm{TM}}$ two-step Visualization System (Envision Detection kit GK500705, Peroxidase/DAB, rabbit/ mouse; DakoCytomation, Glostrup, Denmark). The next steps were performed according to the manufacturer's instructions.

Statistical analysis. The statistical analysis was performed using SPSS 19.0 (SPSS, Inc., Chicago, IL, USA). Values are presented as the mean \pm SEM. The significant differences between the tumor, tumor adjacent and surrounding tissues were assessed by the paired samples t-test. The correlation between periostin gene expression and the clinicopathological characteristics of the NSCLC patients was analyzed by the independent samples t-test. The Kaplan-Meier method was used to generate survival curves, and survival differences were analyzed with the log-rank test, based on the status of periostin expression. Uni- and multivariate analyses were performed using Cox's proportional hazards regression model. $\mathrm{P}<0.05$ was considered to indicate a statistically significant difference.

\section{Results}

Expression of periostin $m R N A$ and protein in each tissue. At the mRNA level, the difference between the expression in the cancer tissue and normal tissue was not significant (Table II). The western blot analysis showed that the periostin level was elevated in the cancer tissue of the NSCLC patients (Fig. 1). The periostin protein gray scale levels of cancer, paratumor and normal tissues were $1.810 \pm 0.415,0.857 \pm 0.130$ and $0.808 \pm 0.100$, respectively (Table II and Fig. 2). The protein level of periostin in the cancer tissues was significantly higher than in the paratumor $(\mathrm{P}=0.000)$ and normal $(\mathrm{P}=0.017)$ tissues. 
Table II. Expression of periostin mRNA and protein in three types of tissues of NSCLC patients.

\begin{tabular}{lcccc}
\hline Group & Periostin mRNA & P-value & Periostin protein & P-value \\
\hline Cancer tissue & $0.326 \pm 0.086$ & - & $1.810 \pm 0.415$ & - \\
Paratumor tissue $^{\mathrm{a}}$ & - & - & $0.857 \pm 0.130$ & $0.000^{\mathrm{b}}$ \\
Normal tissue & $0.389 \pm 0.085$ & $0.433^{\mathrm{c}}$ & $0.808 \pm 0.100$ & $0.017^{\mathrm{c}}$ \\
\hline
\end{tabular}

${ }^{a}$ At the mRNA level, periostin expression was not detected in the paratumor tissue. Data, with the exception of P-value, are presented as the mean \pm SEM. Periostin expression: ${ }^{b}$ Difference between cancer tissue and paratumor tissue; ${ }^{c}$ difference between cancer tissue and normal tissue. NSCLC, non-small cell lung cancer.

Table III. Expression of periostin mRNA and protein in three types of tissues of benign lung tumors.

\begin{tabular}{|c|c|c|c|c|}
\hline Group & Periostin mRNA & P-value & Periostin protein & P-value \\
\hline Tumor tissue & $0.237 \pm 0.077$ & - & $1.178 \pm 0.160$ & - \\
\hline Adjacent tissue $^{\mathrm{a}}$ & - & - & $0.520 \pm 0.161$ & $0.016^{\mathrm{b}}$ \\
\hline Surrounding tissue & $0.460 \pm 0.230$ & $0.378^{\mathrm{c}}$ & $0.235 \pm 0.111$ & $0.001^{\mathrm{c}}$ \\
\hline
\end{tabular}

${ }^{a}$ At the mRNA level, periostin expression was not detected in the adjacent tissue. Data, with the exception of P-value, are presented as the mean \pm SEM. Periostin expression: ${ }^{b}$ Difference between tumor tissue and adjacent tissue; ${ }^{c}$ difference between tumor tissue and surrounding tissue.

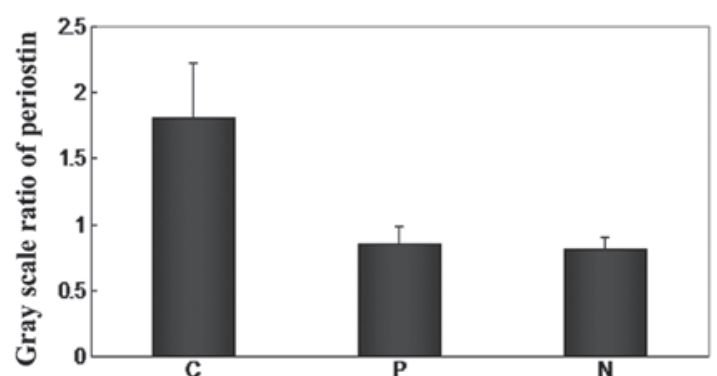

Figure 2. The protein level of periostin in different lung tissues. Lane C, cancer tissue; lane $\mathrm{P}$, paratumor tissue; lane N, normal tissue. The periostin protein gray scale levels of cancer tissues, paratumor tissues and normal tissues were $1.810 \pm 0.415,0.857 \pm 0.130$ and $0.808 \pm 0.100$, respectively.

However, there were no differences between the paratumor tissues and normal tissues $(\mathrm{P}=0.978)$. Periostin expression was also analyzed in 6 benign lung tumors (including 3 inflammatory pseudotumors and 3 pulmonary tuberculosis), and higher expression was observed at the protein level in the pseudotumors and tuberculosis than in the adjacent and surrounding tissues (Table III; $\mathrm{P}<0.05$ ). In addition, there was no prominent difference between the NSCLC patients and the benign lung tumor patients (data not shown).

Correlation between periostin expression and the clinicopathological characteristics of NSCLC patients. The correlation between periostin expression and the clinicopathological characteristics of the NSCLC patients was analyzed, and the result is shown in Table IV. As indicated in this table, the expression of periostin had no correlation with age, pathological type, TNM stage, lymph node status, smoking history, tumor size or invasiveness. Periostin gene expression (at the
mRNA and protein level) was shown to correlate with the gender of the NSCLC patients; the value of the mRNA and the gray scale level of protein in the male group was $1.438 \pm 0.427$ and $3.915 \pm 0.663$, respectively, while those of the female group were $0.449 \pm 0.117$ and $1.463 \pm 0.202$, respectively. Statistical significance was determined by the independent samples t-test (Table IV; $\mathrm{P}<0.05$ ).

Locating periostin in NSCLC by immunohistochemistry. To investigate the location of periostin in NSCLC, immunohistochemistry was carried out on 3 ADC slides and 3 squamous carcinoma slides. The immunostaining indicated that high levels of periostin were present in the mesenchymal areas, but not in the cancer cells themselves. Certain samples were highly stained and others demonstrated no staining (Fig. 3).

Prognostic significance of periostin expression. A Kaplan-Meier analysis indicated that the NSCLC patients whose tumors showed high levels of periostin expression (periostin-H) had significantly shorter overall survival times compared with those with low levels of periostin expression (periostin-L; $\mathrm{P}=0.036$, log-rank test; Fig. 4). The 3-year survival rate was $81.5 \%$ for patients with periostin-L $(n=27)$, and $45.4 \%$ for patients with periostin- $\mathrm{H}(\mathrm{n}=22)$. A univariate analysis was also performed to evaluate the associations between patient prognosis and other factors, including age ( $<60$ vs. $\geq 60$ years), gender (male vs. female), pT status (T1 vs. T2-4), pathological node (pN) status (N0 vs. N1 and N2), histological type (ADC vs. non-ADC), smoking history (smoker vs. never-smoker) and periostin expression (periostin-H vs. periostin-L). Among these parameters, advanced $\mathrm{pN}$ status $(\mathrm{P}=0.044)$ and periostin status $(\mathrm{P}=0.044)$ were significantly associated with a poor prognosis. Since 

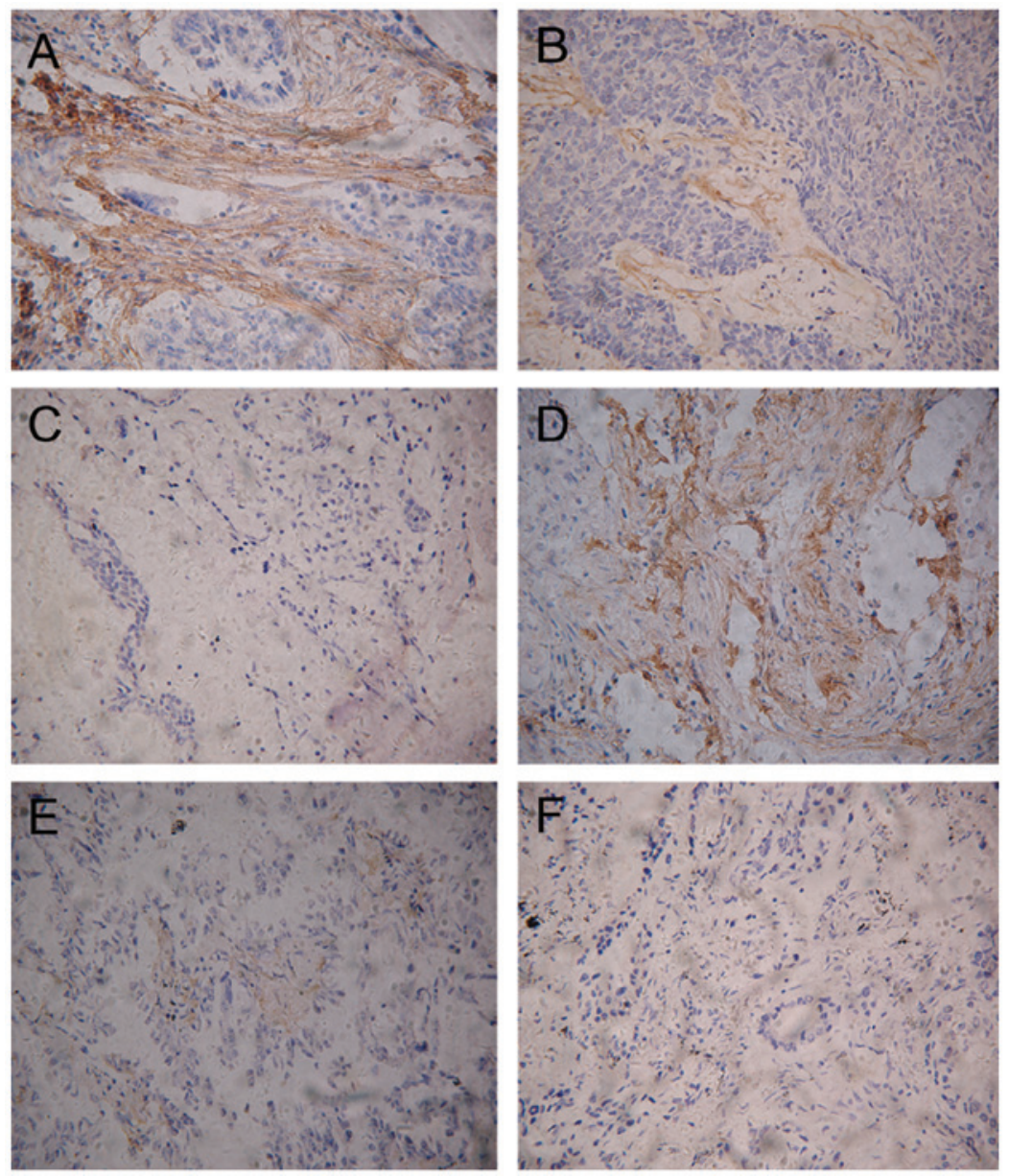

Figure 3. Expression of periostin in non-small cell lung cancer (NSCLC) by immunohistochemistry. (A) Highly-stained squamous carcinoma. (B) Weakly-stained squamous carcinoma. (C) No staining of squamous carcinoma. (D) Highly-stained ADC. (E) Weakly-stained ADC. (F) No staining of ADC. ADC, adenocarcinoma. (Mayer's hematoxylin stain; magnification, x200).

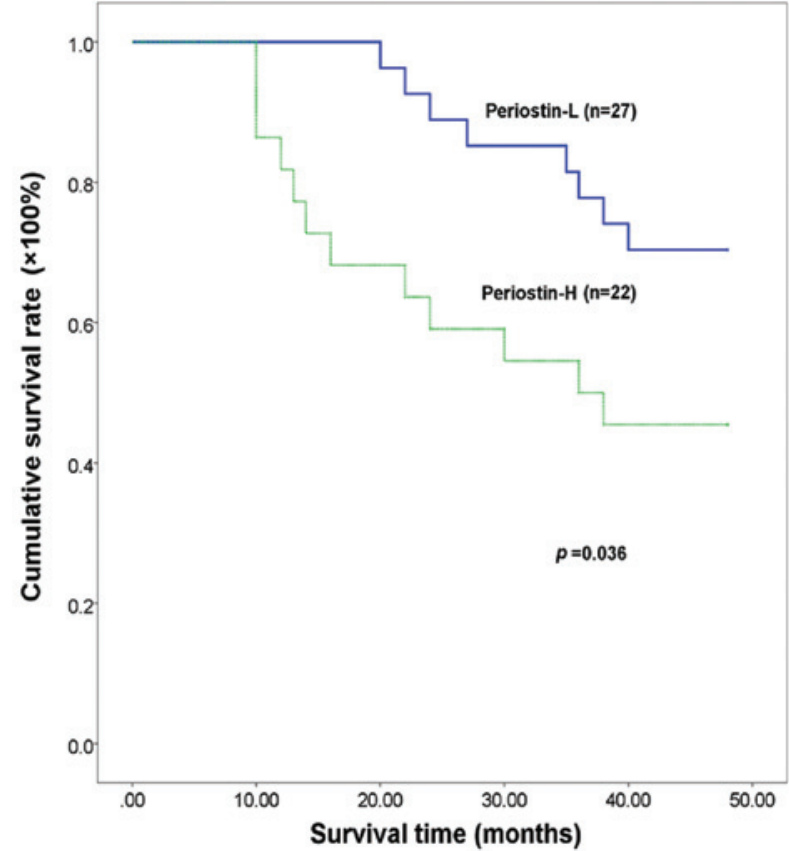

Figure 4. Kaplan-Meier analysis of tumor-specific survival in all non-small cell lung cancer (NSCLC) patients according to periostin expression level. The 3-year survival rate was $81.5 \%$ for patients with low-level periostin expression (periostin- $\mathrm{L} ; \mathrm{n}=27$ ), and $45.4 \%$ for patients with high-level periostin expression (periostin- $\mathrm{H} ; \mathrm{n}=22$ ). the variables shown to have prognostic affects by univariate analysis may represent covariates, all significant variables from the univariate analysis were included in the multivariate regression analysis in order to identify independent prognostic factors. The resulting data are presented in Table V. Periostin expression was identified as an independent prognostic factor $(\mathrm{P}=0.011)$.

\section{Discussion}

Periostin is homologous with fasciclin I, a protein expressed on the surface of a subset of axon pathways in the embryonic central nervous system in insects. Fasciclin I supports cell aggregation and mediates cell sorting, and disruption of fasciclin I causes defects in axonogenesis (19). In mammals, another novel protein that has a similar structure is $\beta$ ig-h3, which was originally cloned as a molecule induced by TGF- $\beta$. Big-h3 promotes adhesion and spreading of fibroblasts in vitro, and may be associated with microfibrils in vivo. Periostin is also a TGF- $\beta$-induced extracellular matrix protein involved in cell survival, angiogenesis, invasion and metastasis (20).

Periostin is overexpressed in the tumor tissue of a number of human tumors, and a similar result is shown in the serum of lung cancer (16) and thymoma (21) patients. The mechanism by which periostin interacts with tumors has not been completely 
Table IV. Expression of periostin in NSCLC cancer tissue and its correlation with clinicopathological characteristics of NSCLC patients.

\begin{tabular}{|c|c|c|c|c|}
\hline Parameter & Periostin mRNA & P-value & Periostin protein & P-value \\
\hline \multicolumn{5}{|l|}{ Gender } \\
\hline Male & $1.438 \pm 0.427$ & \multirow[t]{2}{*}{0.010} & $3.915 \pm 0.663$ & \multirow[t]{2}{*}{0.001} \\
\hline Female & $0.449 \pm 0.117$ & & $1.463 \pm 0.202$ & \\
\hline \multicolumn{5}{|l|}{ Age, years } \\
\hline$<60$ & $0.742 \pm 0.104$ & \multirow[t]{2}{*}{0.085} & $2.468 \pm 0.490$ & \multirow[t]{2}{*}{0.075} \\
\hline$\geq 60$ & $1.913 \pm 0.809$ & & $4.663 \pm 1.060$ & \\
\hline \multicolumn{5}{|l|}{ Pathological type } \\
\hline $\mathrm{ADC}$ & $0.669 \pm 0.096$ & \multirow[t]{2}{*}{0.029} & $3.068 \pm 0.665$ & \multirow[t]{2}{*}{0.566} \\
\hline Non-ADC & $1.939 \pm 0.754$ & & $3.701 \pm 0.897$ & \\
\hline \multicolumn{5}{|l|}{ TNM stage } \\
\hline $\mathrm{I}+\mathrm{II}$ & $0.982 \pm 0.193$ & \multirow[t]{2}{*}{0.534} & $3.688 \pm 0.880$ & \multirow[t]{2}{*}{0.543} \\
\hline III+IV & $1.403 \pm 0.612$ & & $3.016 \pm 0.649$ & \\
\hline \multicolumn{5}{|c|}{ Lymph node status } \\
\hline+ & $1.347 \pm 0.557$ & \multirow[t]{2}{*}{0.621} & $3.859 \pm 0.759$ & \multirow[t]{2}{*}{0.255} \\
\hline- & $1.008 \pm 0.216$ & & $2.613 \pm 0.708$ & \\
\hline \multicolumn{5}{|l|}{ Smoking history } \\
\hline$\geq 20$ pack year & $1.159 \pm 0.197$ & \multirow[t]{2}{*}{0.895} & $4.350 \pm 0.927$ & \multirow[t]{2}{*}{0.059} \\
\hline$<20$ pack year & $1.249 \pm 0.645$ & & $2.319 \pm 0.446$ & \\
\hline \multicolumn{5}{|c|}{ Tumor size and invasiveness } \\
\hline $\mathrm{T} 1+\mathrm{T} 2$ & $0.997 \pm 0.148$ & \multirow[t]{2}{*}{0.538} & $3.356 \pm 0.684$ & \multirow[t]{2}{*}{0.948} \\
\hline $\mathrm{T} 3+\mathrm{T} 4$ & $1.784 \pm 1.222$ & & $3.275 \pm 0.723$ & \\
\hline
\end{tabular}

Data, with the exception of P-value, are presented as the mean \pm SEM. NSCLC, non-small cell lung cancer; ADC, adenocarcinoma.

Table V. Prognostic factors in Cox's proportional hazards model.

\begin{tabular}{lcccccc}
\hline Variables & Risk ratio & Univariate 95\% CI & P-value & Risk ratio & Multivariate 95\% CI & P-value \\
\hline $\begin{array}{l}\text { Age, years } \\
<60 / \geq 60\end{array}$ & 1.635 & $0.680-3.933$ & 0.272 & 2.425 & $0.857-6.859$ & 0.095 \\
$\begin{array}{l}\text { Gender } \\
\text { Male/female } \\
\text { pT status } \\
\text { pT2-4/pT1 } \\
\text { pN status } \\
\text { pN1-2/pN0 }\end{array}$ & 0.541 & $0.159-1.849$ & 0.328 & 0.962 & $0.207-4.460$ & 0.960 \\
$\begin{array}{l}\text { Histological type } \\
\text { Non-ADC/ADC }\end{array}$ & 0.329 & $0.076-1.420$ & 0.136 & 0.416 & $0.084-2.061$ & 0.282 \\
$\begin{array}{l}\text { Smoking history } \\
\text { Smoker/non-smoker }\end{array}$ & 0.353 & $0.128-0.974$ & $0.044^{\mathrm{a}}$ & 0.431 & $0.152-1.224$ & 0.114 \\
$\begin{array}{c}\text { Periostin expression } \\
\text { Periostin-H/L }\end{array}$ & 0.708 & $0.289-1.733$ & 0.450 & 0.987 & $0.335-2.905$ & 0.981 \\
\hline
\end{tabular}

aSignificance: CI, confidence interval; ADC, adenocarcinoma; POSTN, periostin; pT, pathological primary tumor; pN, pathological node.

elucidated. The majority of analyses have shown that periostin stimulated tumor growth by connecting with integrins, particularly $\alpha v \beta 3, \alpha v \beta 5$ and $\alpha 6 \beta 4$. Zhu et al demonstrated that recombinant periostin promoted adhesion and migration of epithelial ovarian tumor cells, and that this function was inhibited by the $\alpha v \beta 3$ or $\alpha v \beta 5$ antibody, indicating that periostin 
is important in the $\alpha v \beta 3$ or $\alpha v \beta 5$ integrin-dependent adhesion and migration of epithelial cells (5). Further studies showed that periostin is the ligand of $\alpha v \beta 3$ and $\alpha v \beta 5$ integrins in breast (11), colon (12) and oral (22) cancer cells. In pancreatic cancer cells, the $\alpha 6 \beta 4$-integrin complex acts as the cell receptor of periostin, and this interaction promotes migration through phosphorylation of focal adhesion kinase (FAK) and protein kinase B (AKT) through activation of the PI3 kinase pathway (15). In a previous study, we demonstrated that periostin promotes the proliferation and migration of the human lung ADC cell line (A549) in vitro by the EMT pathway (18). Malanchi et al (23) showed that periostin was required for cancer stem cell maintenance and that blocking its function prevents metastasis. Periostin recruits Wnt ligands and thereby increases Wnt signaling in cancer stem cells.

In the present study, periostin expression was detected in the tumor, paratumor and normal tissues, and the clinical significance of periostin in the progression and development of NSCLC was observed. The genome was not exactly the same in the paratumor tissue and precancerous lesions, but they were almost identical in histomorphology. When the changes in molecular biology and gene map in the process of tumor progression and development were discussed, the paratumor was selected, and the relative normal tissue from the same patient acted as the control.

Periostin protein levels of the tumor, paratumor and normal tissues of 49 NSCLC patients were detected in the present study. It was demonstrated that the protein level of periostin was much higher in the tumor tissue than in the other 2 groups, but that there was no difference between the paratumor and normal tissues. These findings are similar to the majority of other types of epithelial cancer, including breast (11) and colon (12) cancer. There was no difference between the paratumor and normal tissues at the protein level, therefore periostin was analyzed in the tumor and normal tissue at the mRNA level. However, there was no significant difference between the tumor and normal tissues at the mRNA level. It is well known that mRNA reflects the transcriptional level and protein reflects the translocational level. In the present study, the mRNA level was not consistent with the protein level. The ribosome-loading regulation system and miRNA are likely to play an important role in the translocation of the periostin gene. There are several levels of regulation from transcription to translocation, and mRNAs either degrade or stop translocation in the process. The protein level of periostin is notable with regard to illustrating the function of the gene. Periostin is a novel molecule in the progression and development of NSCLC.

In the present study, the level of periostin was higher in the tumors from the male and non-ADC groups. These findings are also supported by the study of Soltermann et al (24), which showed that the high expression of periostin in either the stroma or tumor epithelia was detected in NSCLC tissues by immunohistochemistry, particularly in the male study group. The majority of non-ADC tumors in this study were squamous carcinomas. It is well known that lung squamous cell carcinoma is a male-dominated cancer. Puglisi et al (25) showed that periostin was significantly correlated with the expression of the estrogen and progesterone receptors in breast cancer, thus providing a reason why periostin is overexpressed in male and squamous cell carcinoma. However, tobacco smoking may be the most important reason behind this. In the present data, the periostin expression of the patients who had a smoking history (4.350 \pm 0.927$)$ was higher than those who did not smoke $(2.319 \pm 0.446)$, although there was no statistically significant difference. Tobacco produces $>4,000$ chemical substances, and $1 / 80$ of them are carcinogenic. Studies have indicated that the polycyclin aromatic and nitroso compounds in the smoke damage the bronchial epithelial cell DNA through a variety of mechanisms, and activate oncogenes (Ras) and deactivate anti-oncogenes (p53). The bronchial epithelial cells transform into cancer cells via this process $(26,27)$. Periostin may be a promoter in this process.

In the present study, periostin was highly expressed in the chronic inflammation patients. It is well known that chronic inflammation may act as tumor promoter. Examples of this may be seen in studies of MALT lymphoma (28) and intestinal carcinogenesis (29). In the present study, there is no direct evidence to reveal the correlation between chronic inflammation and NSCLC. A group of proteins, known as the matricellular proteins, which include thrombospondin (TSP-1 and TSP-2), SPARC (secreted protein acidic and rich in cysteine), osteopontin (OPN), the tenascins (TN-C and $\mathrm{TN}-\mathrm{X}$ ) and the CCN family members (CCN1-6), are known to be expressed at lower levels in normal adult tissue, but are upregulated during wound healing and tissue remodeling. The expression of these proteins is also involved in tumor development and progression. In normal situations, these proteins are well controlled by various signals. However, in tumors, the expression of the matricellular proteins is defined in a deregulated manner as a 'wound that does not heal' (30). In the present study, periostin was upregulated in the NSCLC and chronic inflammation patients, therefore we hypothesize that periostin may be a member of the matricellular protein family and that it has an effect on chronic inflammation and cancer. Periostin may be a suitable target to block the dangerous loop between cancer and inflammation.

Using immunohistochemistry, the present study showed that periostin was only located in the mesenchymal tissue surrounding the tumor cells. This corresponded to the location of periostin previously identified in other types of cancer cells $(5,6,11,12)$. In the present study, the pattern of the localization of periostin in the tumoral stroma appears typically fibrillar and branched, suggesting a possible association between periostin and the fibers of the desmoplastic stroma of NSCLC. Recently, immunoelectron microscopy analyses of mouse periodontal ligaments has revealed a close association between periostin and collagen fibers, indicating that a similar association may take place in NSCLC tissues (31).

The localization and function of periostin in the juxtatumoral stroma exhibits similarities to other secreted proteins, such as the CCN family of proteins. The CCN family is a group of 6 secreted proteins that are specifically associated with the extracellular matrix. Similar to periostin, CNN family members are induced by growth factors and cytokines, such as TGF- $\beta$ and endothelin 1 , and cellular stress, including hypoxia, and are overexpressed in pathological conditions that affect connective tissues, including scarring, fibrosis and cancer. They also interact with integrins and act as matricellular proteins to mediate cell adhesion, migration, tissue repair (32), fibrosis (33), cancer and vascular disease (34). 
For the present survival analysis, the 3-year overall survival rate for the patients with periostin-L expression was much higher than for those with periostin-H expression. Furthermore, the multivariate analysis revealed that periostin- $\mathrm{H}$ expression was an independent prognostic factor. The results indicate that periostin is a crucial prognostic factor. These findings lead us to believe that the overexpression of periostin is likely to represent an important transformation factor associated with a more malignant phenotype in NSCLC patients.

In conclusion, although the present study involved only 49 patients, it may be concluded that periostin is important in the progression and development of NSCLC. There was an abnormally high expression level of periostin in the NSCLC and lung chronic inflammation patients, and the periostin expression level was much higher in the male and non-ADC groups of NSCLC patients. We considered that periostin may be pivotal in the pathogenesis and development of NSCLC, and that chronic inflammation may promote cancer development using certain molecules, including periostin. It was demonstrated that periostin was only located in the juxtatumoral stroma of the NSCLC tissues, along with those proteins belonging to the $\mathrm{CCN}$ family members, which had been shown to be integrin-dependent. Patients with high level of periostin achieved a significantly inferior outcome, indicating that it is a malignant phenotype in NSCLC.

\section{Acknowledgements}

This study was supported by grants from the National Natural Science Foundation of China (grant no. 81001039), Nanjing City Medical Technology Development Project (grant no. QYK10138 ), Engineering Training the Young Medical Talents in Nanjing City and the Six Talent Peaks in Jiangsu Province to Dr L. Hong.

\section{References}

1. Jemal A, Bray F, Center MM, Ferlay J, Ward E and Forman D: Global cancer statistics. CA Cancer J Clin 61: 69-90, 2011.

2. Takeshita S, Kikuno R, Tezuka K and Amann E: Osteoblastspecific factor 2: cloning of a putative bone adhesion protein with homology with the insect protein fasciclin I. Biochem J 294: 271-278, 1993.

3. Kruzynska-Frejtag A, Wang J, Maeda M, Rogers R, Krug E, Hoffman S, Markwald RR and Conway SJ: Periostin is expressed within the developing teeth at the sites of epithelial-mesenchymal interaction. Dev Dyn 229: 857-868, 2004.

4. Kudo Y, Siriwardena BS, Hatano H, Ogawa I and Takata T: Periostin: novel diagnostic and therapeutic target for cancer. Histol Histopathol 22: 1167-1174, 2007.

5. Zhu M, Fejzo MS, Anderson L, Dering J, Ginther C, Ramos L, Gasson JC, Karlan BY and Slamon DJ: Periostin promotes ovarian cancer angiogenesis and metastasis. Gynecol Oncol 119 337-344, 2010

6. Tai IT, Dai M and Chen LB: Periostin induction in tumor cell line explants and inhibition of in vitro cell growth by anti-periostin antibodies. Carcinogenesis 26: 908-915, 2005.

7. Horiuchi K, Amizuka N, Takeshita S, Takamatsu H, Katsuura M, Ozawa H, Toyama Y, Bonewald LF and Kudo A: Identification and characterization of a novel protein, periostin, with restricted expression to periosteum and periodontal ligament and increased expression by transforming growth factor beta. J Bone Miner Res 14: 1239-1249, 1999.

8. Ji X, Chen D, Xu C, Harris SE, Mundy GR and Yoneda T: Patterns of gene expression associated with BMP-2-induced osteoblast and adipocyte differentiation of mesenchymal progenitor cell 3T3-F442A. J Bone Miner Metab 18: 132-139, 2000.
9. Lorts A, Schwanekamp JA, Elrod JW, Sargent MA and Molkentin JD: Genetic manipulation of periostin expression in the heart does not affect myocyte content, cell cycle activity, or cardiac repair. Circ Res 104: e1-e7, 2009.

10. Utispan K, Thuwajit P, Abiko Y, Charngkaew K, Paupairoj A, Chau-in S and Thuwajit C: Gene expression profiling of cholangiocarcinoma derived fibroblast reveals alterations related to tumor progression and indicates periostin as a poor prognostic marker. Mol Cancer 9: 13, 2010.

11. Zhang Y, Zhang G, Li J, Tao Q and Tang W: The expression analysis of periostin in human breast cancer. J Surg Res 160: 102-106, 2010.

12. Bao S, Ouyang G, Bai X, Huang Z, Ma C, Liu M, Shao R, Anderson RM, Rich JN and Wang XF: Periostin potently promotes metastatic growth of colon cancer by augmenting cell survival via the Akt/PKB pathway. Cancer Cell 5: 329-339, 2004.

13. Michaylira CZ, Wong GS, Miller CG, Gutierrez CM, Nakagawa H, Hammond R, Klein-Szanto AJ, Lee JS, Kim SB, Herlyn M, Diehl JA, Gimotty P and Rustgi AK: Periostin, a cell adhesion molecule, facilitates invasion in the tumor microenvironment and annotates a novel tumor-invasive signature in esophageal cancer. Cancer Res 70: 5281-5292, 2010.

14. Kudo Y, Ogawa I, Kitajima S, Kitagawa M, Kawai H, Gaffney PM, Miyauchi $\mathrm{M}$ and Takata T: Periostin promotes invasion and anchorage-independent growth in the metastatic process of head and neck cancer. Cancer Res 66: 6928-6935, 2006.

15. Baril P, Gangeswaran R, Mahon PC, Caulee K, Kocher HM, Harada T, Zhu M, Kalthoff H, Crnogorac-Jurcevic T and Lemoine NR: Periostin promotes invasiveness and resistance of pancreatic cancer cells to hypoxia-induced cell death: role of the beta4 integrin and the PI3k pathway. Oncogene 26: 2082-2094, 2007.

16. Sasaki H, Dai M, Auclair D, Fukai I, Kiriyama M, Yamakawa Y, Fujii Y and Chen LB: Serum level of the periostin, a homologue of an insect cell adhesion molecule, as a prognostic marker in nonsmall cell lung carcinomas. Cancer 92: 843-848, 2001.

17. Morra L, Rechsteiner M, Casagranda S, Teichman A, Schraml P, Moch $\mathrm{H}$ and Soltermann A: Characterization of periostin isoform pattern in non-small cell lung cancer. Lung Cancer 76: 183-190, 2012.

18. Hong LZ, Sun HM, Lv XJ, Yang D, Zhang JN and Shi Y: Expression of periostin in the serum of NSCLC and its function on proliferation and migration of human lung adenocarcinoma cell line (A549) in vitro. Mol Biol Rep 37: 2285-2293, 2010.

19. Wang WC, Zinn K and Bjorkman PJ: Expression and structural studies of fasciclin I, an insect cell adhesion molecule. J Biol Chem 268: 1448-1455, 1993.

20. Kim JE, Kim SJ, Lee BH, Park RW, Kim K and Kim IS: Identification of motifs for cell adhesion within the repeated domains of transforming growth factor-beta-induced gene, betaig-h3. J Biol Chem 275: 30907-30915, 2000.

21. Sasaki H, Dai M, Auclair D, Kaji M, Fukai I, Kiriyama M, Yamakawa Y, Fujii Y and Chen LB: Serum level of the periostin, a homologue of an insect cell adhesion molecule, in thymoma patients. Cancer Lett 172: 37-42, 2001.

22. Kudo Y, Takata T, Ogawa I, Kaneda T, Sato S, Takekochi T, Zhao M, Miyauchi M and Nikai H: p27Kipl accumulation by inhibition of proteasome function induces apoptosis in oral squamous cell carcinoma cells. Clin Cancer Res 6: 916-923, 2000.

23. Malanchi I, Santamaria-Martínez A, Susanto E, Peng H, Lehr HA, Delaloye JF and Huelsken J: Interactions between cancer stem cells and their niche govern metastatic colonization. Nature 481: 85-89, 2012.

24. Soltermann A, Tischler V, Arbogast S, Braun J, Probst-Hensch N, Weder W, Moch H and Kristiansen G: Prognostic significance of epithelial-mesenchymal and mesenchymal-epithelial transition protein expression in non-small cell lung cancer. Clin Cancer Res 14: 7430-7437, 2008.

25. Puglisi F, Puppin C, Pegolo E, Andreetta C, Pascoletti G, D'Aurizio F, Pandolfi M, Fasola G, Piga A, Damante G and Loreto CD: Expression of periostin in human breast cancer. J Clin Pathol 61: 494-498, 2008.

26. Vineis P, Alavanja M, Buffler P, Fontham E, Franceschi S, Gao YT, Gupta PC, Hackshaw A, Matos E, Samet J, Sitas F, Smith J, Stayner L, Straif K, Thun MJ, Wichmann HE, Wu AH, Zaridze D, Peto R and Doll R: Tobacco and cancer: recent epidemiological evidence. J Natl Cancer Inst 96: 99-106, 2004.

27. International Agency for Research on Cancer. Tobacco smoking. IARC monographs on the evaluation of carcinogenic risks to humans. Vol. 38. IARC, Lyon, 1986. 
28. Wotherspoon AC, Ortiz-Hidalgo C, Falzon MR and Isaacson PG Helicobacter pylori-associated gastritis and primary B-cell gastric lymphoma. Lancet 338: 1175-1176, 1991.

29. Wang WH, Huang JQ, Zheng GF, Lam SK, Karlberg J and Wong BC: Non-steroidal anti-inflammatory drug use and the risk of gastric cancer: a systematic review and meta-analysis. J Natl Cancer Inst 95: 1784-1791, 2003.

30. Dvorak HF: Tumors: wounds that do not heal. Similarities between tumor stroma generation and wound healing. N Engl J Med 315: 1650-1659, 1986.

31. Rakian A, Yang WC, Gluhak-Heinrich J, Cui Y, Harris MA, Villarreal D, Feng JQ, Macdougall M and Harris SE: Bone morphogenetic protein-2 gene controls tooth root development in coordination with formation of the periodontium. Int J Oral Sci 5: 75-84, 2013.
32. Lin CG, Chen CC, Leu SJ, Grzeszkiewicz TM and Lau LF: Integrin-dependent functions of the angiogenic inducer NOV (CCN3): implication in wound healing. J Biol Chem 280: 8229-8237, 2005.

33. Leask A and Abraham DJ: The role of connective tissue growth factor, a multifunctional matricellular protein, in fibroblast biology. Biochem Cell Biol 81: 355-363, 2003.

34. Holloway SE, Beck AW, Girard L, Jaber MR, Barnett CC Jr, Brekken RA and Fleming JB: Increased expression of Cyr61 (CCN1) identified in peritoneal metastases from human pancreatic cancer. J Am Coll Surg 200: 371-377, 2005. 